\title{
Kinetic and thermodynamic characterizations of thermal inactivation of the inulinase produced by Kluyveromyces latics
}

\author{
Zhao Zhao ${ }^{\text {a }}$, Zhiping Zhao ${ }^{\mathrm{b} *}$, Xingya Wang ${ }^{\mathrm{c}}$ \\ School of Chemical Engineering and the Environment, Beijing Institute of Technology, Beijing \\ 100081, China. \\ azhaozhao851023@163.com, ${ }^{\text {b*zhaozp@bit.edu.cn, }{ }^{c} 592484616 @ q q . c o m}$ \\ Corresponding Author: Zhiping Zhao
}

Keywords: inulinase, inactivation, kinetic, thermodynamic

\begin{abstract}
The present study evaluated the kinetics and thermodynamic parameters for the thermal inactivation of inulinase. The thermoinactivation behaviours of inulinase under $40,50,60$ and $70^{\circ} \mathrm{C}$ were observed. Residue activity of inulinase after incubated for a certain time under the tested temperatures, respectively. The inactivation rate constants $\left(k_{\text {in }}\right)$ of inulinase under different temperatures were calculated and used to estimate the activation energy for irreversible inactivation $E_{\mathrm{a}(\mathrm{in})}$ of inulinase, which was $236.9 \mathrm{~kJ} \mathrm{~mol}^{-1}$.
\end{abstract}

\section{Introduction}

Bioethanol, considered as the recommended alternative fuel for gasoline, has been into human sights for decades of years. The energy crops that are used as the raw materials of bioethanol should be non-food crop, which can be planted in nonfarm land [1]. Jerusalem artichoke (Helianthus tuberosus L ) , tuberous-rooted perennial of the family Asteraceae, is a kind of non-food bioenergy crop which can flourish on most soils even on the tidal flat [2] or desert. Inulin, the main component of the Jerusalem artichoke tuber, is employed to produce fermentable sugar which is the raw material of bioethanol fermentation. Inulin consists of linear chains of $\beta-2 \rightarrow 1-D$-fructosfuranose with a glucose molecule at the end. Inulinase hydrolysis of inulin was recommended due to its environmentally sound and no formation of by-products.

To the best of our knowladge, the enzyme employed as the catalyst for hydrolysis of inulin is too expesive to be applied in industrial production. Moreover, inulinase is hard to recover, therefore, the high utilization efficiency of inulinase become a key issue for the fermentable sugar production. A higher reaction temperature is required for the desired fast hydrolysis rate[3], however, the thermo inactivation of inulinase during the hydrolysis reaction will increase the cost of inulinase [4, 5]. In the present work, the thermo inactivation behaviour of inulinase was observed, and provide a basis for the optimization of inulin hydrolysis by inulinase accounting for both the hydrolysis time and the thermo inactivation of inulinase.

\section{Theoretical}

The thermodynamics of the irreversible thermoinactivation of inulinase was determined by rearranging the Eyring's absolute rate equation, derived from the transition state theory[6],

$$
k_{\text {in }}=\left(k_{B} T / h\right) \mathrm{e}^{\left(-\Delta H^{*} / \mathrm{R} T\right)} e^{\left(\Delta S^{*} / R\right)}
$$

where, $h$ represents the Planck's constant $\left(6.63 \times 10^{-34} \mathrm{~J} \mathrm{~s}\right), k_{\mathrm{B}}$ is the Boltzman's constant $\left(1.38 \times 10^{-23} \mathrm{~J}\right.$ $\left.\mathrm{K}^{-1}\right), R$ is the gas constant (8.314 J.K $\left.\mathrm{K}^{-1} \mathrm{~mol}^{-1}\right), \Delta H^{*}, \Delta G^{*}$, and $\Delta S^{*}$ represent enthalpy, free energy, and entropy of inactivation respectively and are introduced in Eqs. (2) - (4).

$$
\Delta H^{*}=E_{a(\text { in })}-\mathrm{R} T
$$




$$
\begin{aligned}
& \Delta G^{*}=-\mathrm{R} T \ln \left(k_{\mathrm{in}} h\right) /\left(k_{\mathrm{B}} T\right) \\
& \Delta S^{*}=\left(\Delta H^{*}-\Delta G^{*}\right) / T \ldots \ldots .
\end{aligned}
$$

The energy barriers of thermoinactivation $E a_{(i n)}$, was estimated by applying the Arrhenius equation (5) and plot.

$\ln k_{\text {in }}=-E_{\mathrm{a}(\mathrm{in})} / \mathrm{R} T$

\section{Materials and methods}

\subsection{Materials.}

Inulin (derived from Jerusalem artichoke purchased from Gansu Likang nutrition and Food Co, Ltd.). Inulinase used in this study was produced by the Kluyveromyces lactis MW270-7B strain [7], Chemicals were purchased from Oxoid Ltd., Basingstoke, Hampshire, England.

\subsection{Microorganism and enzyme production.}

The liquid media for inulinase production contains $1 \%$ yeast extract, $2 \%$ glucose and $2 \%$ peptone. A $500 \mathrm{ml}$ Erlenmeyer flask with $200 \mathrm{ml}$ medium was inoculated with $4 \mathrm{ml}$ seed culture medium and incubated in a rotator shaker at $30{ }^{\circ} \mathrm{C}$ with the stirring speed of $170 \mathrm{rpm}$ for $120 \mathrm{~h}$.

\subsection{Analysises and tests.}

Inulinase solution were incubating in a thermostated bath at three temperature values $(40,50,60$ and $70^{\circ} \mathrm{C}$ ) to observe the thermal inactivation behaviour, respectively. A certain amount of inulinase was sampled to test the inulinase avtivity at every certain time. Inulinase activity was assayed in a reaction mixture containing $0.5 \mathrm{ml}$ appropriately diluted enzyme solution and $0.5 \mathrm{ml} 50 \mathrm{mM}$ sodium acetate buffer, $\mathrm{pH} 4.6$, containing $2 \mathrm{wt} \%$ inulin. After the mixture was incubated at $55^{\circ} \mathrm{C}$ for $15 \mathrm{~min}$, it was heated for $5 \mathrm{~min}$ in boiling water to terminate the reaction. Then, the reducing sugar concentration liberated in the reaction mixture was confirmed by DNS method[8]. One unit (U) inulinase activity was defined as the amount of enzyme required for hydrolyzing inulin to produce $1 \mu \mathrm{M}$ reducing sugar per minute in the reaction mixture [9].

\section{Results and discussion}

\subsection{Inulinase thermal inactivation behaviour}

Fig. 1 shows the inulinase inactivation behaviour at different temperatures. Inulinase almost inactivated completely within 20 minutes under $70^{\circ} \mathrm{C}$, but only lost about $10 \%$ activity when it prolonged to $100 \mathrm{~min}$ under $50^{\circ} \mathrm{C}$. Further more, after being heated under $40^{\circ} \mathrm{C} 100 \mathrm{~min}$, there was no inactivation of the inulinase observed.

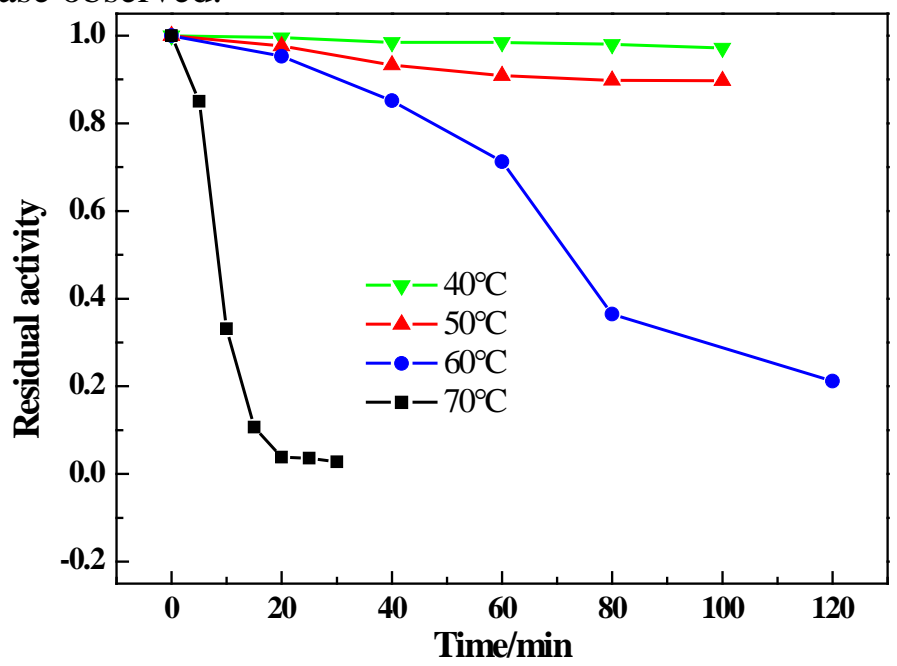

Fig. 1 Inulinase activity changes with time during the inactivation process 


\subsection{Thermodynamics analysis}

$E_{\text {a(in) }}$ is an important indicator of the thermostability of an enzyme. Fig. 5 shows the parameter $E_{\text {a(in) }}$ obtained by applying an Arrhenius plot to the $k_{\text {in }}$ values $\left(-0.001,-0.016,-0.1701\right.$ for $50,60,70^{\circ} \mathrm{C}$, respectively) obtained from Fig. 2-4. The energy barrier of the thermal inactivation process was $236.9 \mathrm{~kJ} \mathrm{~mol}^{-1}$, and was used to calculate the thermodynamic parameters inulinase inactivation using Eqs. 2-4.

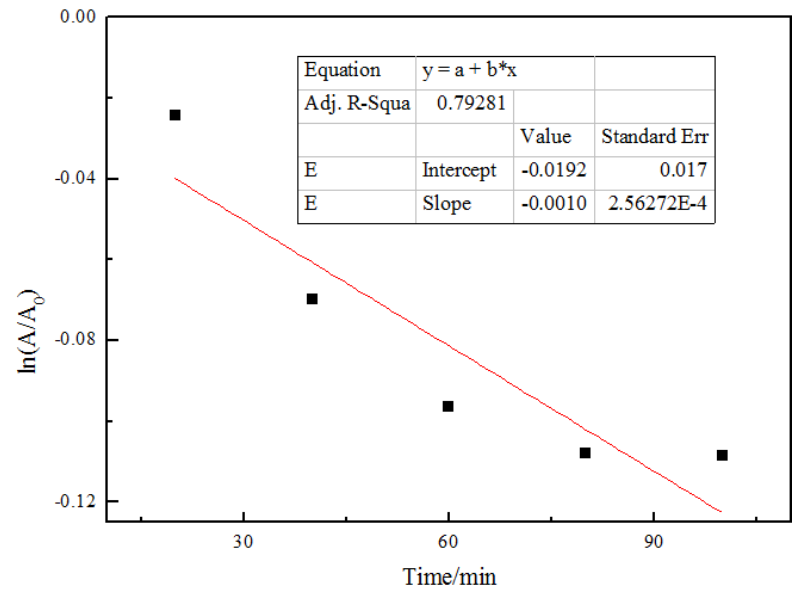

(a)

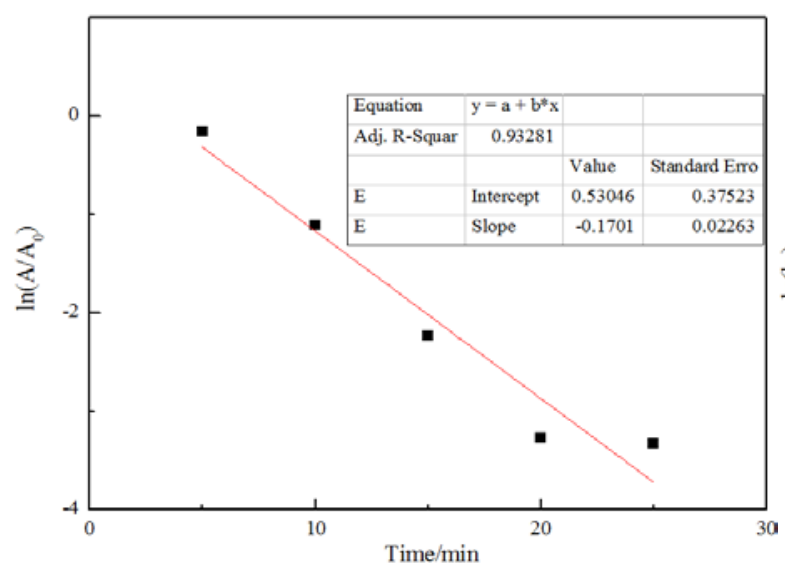

(c)

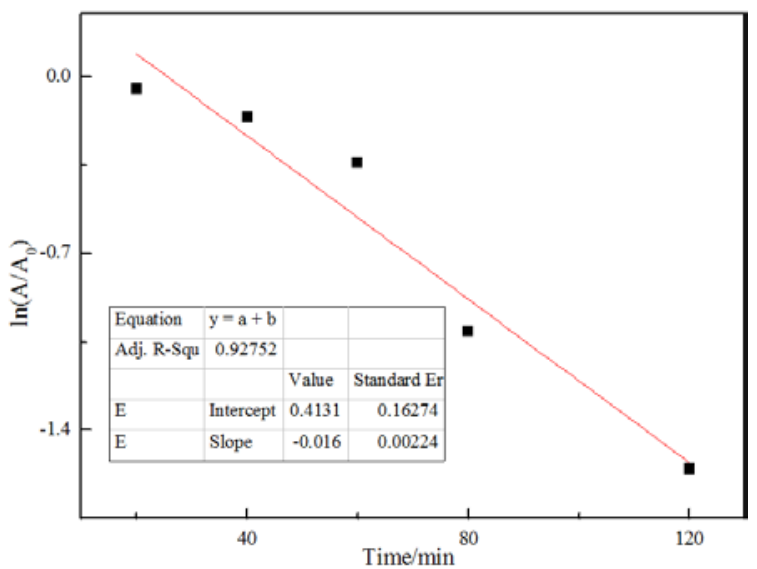

(b)

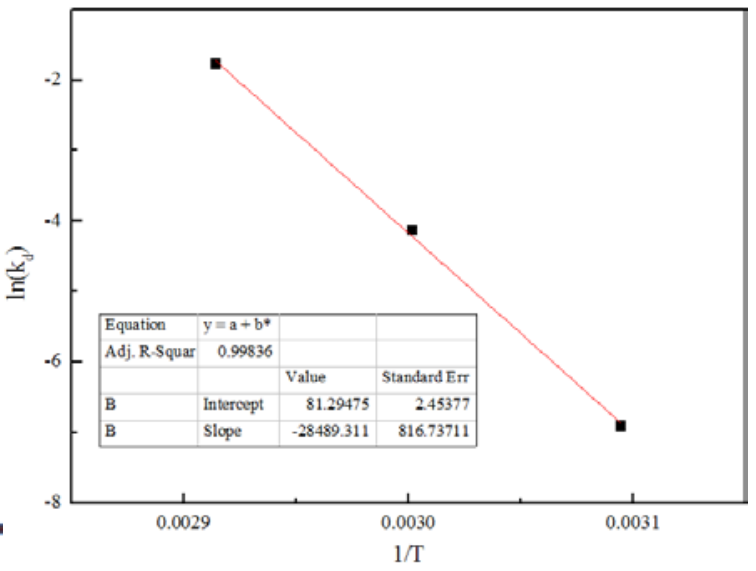

(d)

Fig 2. The natural logarithm of residual activities of inulinase as a function of the incubation time under (a) $50^{\circ} \mathrm{C}$, (b) $60^{\circ} \mathrm{C}$ and (c) $70^{\circ} \mathrm{C}$; and (d) the determination of the inactivation enegy based on Atthenius plot.

Table 1 shows the calculated value of $\Delta H^{*}, \Delta G^{*}$, and $\Delta S^{*}$ at different temperature $\left(50,60,70^{\circ} \mathrm{C}\right)$, respectively. It is clear that, $\Delta G^{*}$ increased with the temperature but $\Delta H^{*}$ and $\Delta S^{*}$ decreased with the temperature.

Table 1 Thermodynamic parameters for irreversible inactivation of inulinase

\begin{tabular}{cccc}
\hline & $\Delta H^{*}\left(\mathrm{~kJ} \mathrm{~mol}^{-1}\right)$ & $\Delta G^{*}\left(\mathrm{~kJ} \mathrm{~mol}^{-1}\right)$ & $\Delta S^{*}\left(\mathrm{~kJ} \mathrm{~mol}^{-1} \mathrm{~K}^{-1}\right)$ \\
\hline $50^{\circ} \mathrm{C}$ & 234.21 & 249.6 & -0.047 \\
$60^{\circ} \mathrm{C}$ & 234.13 & 269.9 & -0.107 \\
$70^{\circ} \mathrm{C}$ & 234.05 & 284.7 & -0.148 \\
\hline
\end{tabular}

For the inulinase used in this study, the most recommended application temperature was between $50-60^{\circ} \mathrm{C}$, which was decided by considering both the hydrolysis rate and the enzyme cost. If the temperature is lower than $50^{\circ} \mathrm{C}$, although the cost of enzyme is negligible, the hydrolysis reaction of 
inulin will take a long time, leading to the high time-cost. When the hydrolysis temperature is carried out at the temperature higher than $60^{\circ} \mathrm{C}$, the initial hydrolysis rate will be very fast. However, along with the reaction time, the inactivation of inulinase occurs fastly, the residual inulinase activity is lower and lower, that may caused slow hydrolysis rate even the incomplete conversion of inulin.

\section{Summary}

The thermal inactivation of inulinase under 50,60 and $70^{\circ} \mathrm{C}$ was observed, respectively. The $E_{\mathrm{a}(\mathrm{in})}$ of inulinase produced by Kluyveromyces lactis $M W 270-7 B$ was calculated. The results shows that the inulinase sustain a stable activity under $50^{\circ} \mathrm{C}$, but inactvated fast under 60 and $70^{\circ} \mathrm{C}$. That is to say, $50{ }^{\circ} \mathrm{C}$ may be the recommend temperature for hydrolysis reaction of inulin when considering the cost of inulinase.

\section{Acknowledgements}

The authors would like to thank the support of the National Natural Science Foundation of China (No. 21276024). We also appreciate associate professor Jianping Liu (State Key Laboratory of Genetic Engineering, Institute of Genetics, School of Life Sciences, Fudan University) for kindly providing us the KLuyveromyces lactis MW270-7B recombinant strain.

\section{References}

[1]. SchorrGalindo, S. and J.P. Guiraud, Sugar potential of different Jerusalem artichoke cultivars according to harvest. Bioresource Technology, 1997. 60(1): p. 15-20.

[2]. Zhao, G., S.K. Mehta, and Z. Liu, Use of saline aquaculture wastewater to irrigate salt-tolerant Jerusalem artichoke and sunflower in semiarid coastal zones of China. Agricultural Water Management, 2010. 97(12): p. 1987-1993.

[3]. Rocha, J.R., et al., Design and characterisation of an enzyme system for inulin hydrolysis. Food Chemistry, 2006. 95(1): p. 77-82.

[4]. Lago, C.C. and C.P.Z. Norena, Kinetic and Thermodynamic of Thermal Inactivation of the Peroxidase, Polyphenoloxidase and Inulinase Activities during Blanching of Yacon (Smallanthus sonchifolius) Juice. Food and Bioprocess Technology, 2014. 7(12): p. 3560-3568.

[5]. Prajapati, V., et al., Kinetic and thermodynamic characterization of lipase produced by Cellulomonas flavigena UNP3. Journal of Basic Microbiology, 2014. 54(9): p. 976-983.

[6]. Siddiqui, K.S., et al., Partial and complete alteration of surface charges of carboxymethylcellulase by chemical modification: thermostabilization in water-miscible organic solvent. Enzyme and Microbial Technology, 1999. 24(8-9): p. 599-608.

[7]. Yu, J., et al., Enhanced expression of heterologous inulinase in Kluyveromyces lactis by disruption of hap1 gene. Biotechnology Letters, 2010. 32(4): p. 507-512.

[8]. Miller, G.L., Use of Dinitrosalicylic Acid Reagent for Determination of Reducing Sugar. Anal. Chem., 1959. 31: p. 426-428.

[9]. Muñoz-Gutiérrez, I., M.E. Rodríguez-Alegría, and A. López Munguía, Kinetic behaviour and specificity of $\beta$-fructosidases in the hydrolysis of plant and microbial fructans. Process Biochemistry, 2009. 44(8): p. 891-898. 